\title{
Amine metabolites in the cerebrospinal fluid in Huntington's chorea
}

\author{
G. CURZON, JOHN GUMPERT, AND DAVID SHARPE \\ From the Institute of Neurology, Queen Square, London, \\ and the Department of Neurology, The United Sheffield Hospitals, Sheffield
}

SUMMARY The amine metabolites HVA and 5-HIAA in the lumbar CSF of 15 patients with Huntington's chorea were determined. A negative correlation was found between the severity of $\frac{\text { क }}{\widetilde{D}}$ symptoms and the CSF HVA, but not 5-HIAA levels. The mean HVA concentration was lower 0 than that of a group of patients with miscellaneous neurological disorders, similar to that of a group $\tilde{D}^{\circ}$ with miscellaneous psychiatric disorders and higher than that of a group with Parkinson's disease. $\vec{O}$ The mean 5-HIAA concentration was similar to that of the neurological group and higher than $\overrightarrow{\vec{\omega}}$ those of the groups with psychiatric disorders or Parkinson's disease. CSF HVA and 5-HIAA concentrations of a single patient with severe akinetic rigid Huntington's chorea were similar to those $\overline{\bar{z}}$ found in Parkinson's disease. The findings are discussed in relation to previous neuropathologicalō observations and to reported effects of drugs on the choreic symptoms.

The deficiency in brain dopamine metabolism in Parkinson's disease (Ehringer and Hornykiewicz, 1960) suggests that the metabolism of dopamine (DA) or other brain amines may also be abnormal in other movement disorders. However, in Huntington's chorea, normal concentrations of DA and its main metabolite homovanillic acid (HVA) have been found in the caudate nucleus and putamen, wherein almost all the brain DA is normally contained, while the HVA concentration in the substantia nigra was 'near normal' (Hornykiewicz, 1966). Urinary DA and HVA concentration are normal (Williams, Maury, and Kibler, 1961; Sourkes, Pirnicki, Brown, Wiseman-Distler, Murphy, Sankoff, and Saint-Cyr, 1965; Rinne, Sonninen and Palo, 1966) but are probably unrelated to brain DA metabolism as they are almost completely derived from extracerebral sources.

So far, there is little information available on the concentration in the cerebrospinal fluid (CSF) of HVA or the 5-hydroxytryptamine (5-HT) metabolite 5-hydroxyindole acetic acid (5-HIAA) in Huntington's chorea. The concentration of HVA in the CSF probably reflects the total turnover of DA in the brain (Guldberg, 1969; Guldberg and Yates, 1968; Gottfries, Gottfries, and Roos, 1969; Chase, Schnur, and Gordon, 1970) and its determination enables some estimate to be made of the latter during

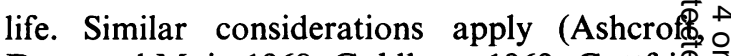
Dow, and Moir, 1968; Guldberg, 1969; Gottfri et al., 1969) though perhaps with less fore $\square$ (Curzon, Gumpert, and Sharpe, 1971) to theco relationship between CSF 5-HIAA and bra 5-HT turnover. Two groups of three patien $\overrightarrow{0}$ with Huntington's chorea have been reported $N$ to have CSF HVA concentrations in the lower region of the normal range (Bernheimer, Birkmayer, and Hornykiewicz, 1966; Aquilonius and Sjostrom, 1971).

In this paper we report the concentrations of $\frac{\mathbb{Q}}{D}$ HVA and 5-HIAA in the lumbar CSF of $15 \overrightarrow{\overrightarrow{7}}$ patients with chorea. Concentrations are compared with the severity of the disease.

Findings in the CSF are also compared with results for groups of miscellaneous neurological patients, psychiatric patients, and patients with? Parkinson's disease.

\section{PATIENTS}

Fifteen patients (eight male and seven female)을 exhibiting choreiform movements and having a history of mental deterioration were examined. Ages ranged from 29 to 65 years and the length of history from one to 12 years. Ten of the patients had a family history of Huntington's chorea, an incidence 0 of $67 \%$. The remaining five cases have been regarded $\mathrm{C}$ as sporadic. It is interesting that the female patients were as a group older and more severely affectedo 
than the males. A further male patient aged 23 years who was seriously disabled by the akinetic rigid form of Huntington's chorea was also studied.

The nature and purpose of the investigation was explained to each patient and to a responsible relative, written consent being obtained in all cases. On admission all medication was withdrawn and none was prescribed until after lumbar puncture. Clinical details are summarized in Table 1.

TABLE 1

DETAILS OF PATIENTS WITH HUNTINGTON'S CHOREA

\begin{tabular}{|c|c|c|c|c|c|c|}
\hline Initials & $\begin{array}{l}\text { Age } \\
(y r)\end{array}$ & $\begin{array}{l}\text { Family } \\
\text { history }\end{array}$ & $\begin{array}{c}\text { Length } \\
\text { of } \\
\text { history } \\
(y r)\end{array}$ & Severity & $\begin{array}{c}H V A \\
(n g / m l .)\end{array}$ & $\begin{array}{l}5-H I A A \\
(n g / m l .)\end{array}$ \\
\hline
\end{tabular}

\begin{tabular}{lcccccc}
\hline Males (8) & & & & & & \\
A.S. & 57 & - & 3 & 20 & 29 & 22 \\
F.N. & 50 & + & 5 & 21 & 26 & 26 \\
R.B. & 37 & + & 5 & 23 & 45 & 23 \\
I.T. & 60 & - & 3 & 25 & 27 & 35 \\
H.L. & 53 & + & 3 & 29 & 22 & 15 \\
K.R. & 34 & + & 1 & 31 & 6 & 19 \\
A.J. & 55 & + & 2 & 31 & 3 & 53 \\
J.C. & 52 & + & 8 & 44 & 13 & 26 \\
Mean values & $50 \pm 9$ & & $4 \pm 2$ & $28 \pm 8$ & $21 \pm 14$ & $29 \pm 12$ \\
& & & & & &
\end{tabular}

\begin{tabular}{lcccccc}
\hline Females (7) & & & & & & \\
P.H. & 29 & - & 4 & 28 & 29 & 23 \\
M.R. & 60 & + & 8 & 32 & 21 & 17 \\
L.W. & 56 & + & 7 & 34 & 51 & 36 \\
N.R. & 62 & - & 5 & 37 & 35 & 25 \\
A.B. & 65 & + & 10 & 49 & 20 & 43 \\
L.T. & 64 & - & 12 & 54 & 6 & 35 \\
E.D. & 48 & + & 10 & 62 & 15 & 29 \\
Mean values & $55 \pm 13$ & & $8 \pm 3$ & $42 \pm 13$ & $25 \pm 15$ & $29 \pm 9$ \\
\hline
\end{tabular}

\begin{tabular}{|c|c|c|c|c|c|}
\hline $\begin{array}{l}\text { Differences } \\
\text { between } \\
\text { males and } \\
\text { females }\end{array}$ & NS & $P<0.02$ & $P<0.05$ & NS & NS \\
\hline $\begin{array}{l}\text { Mean value } \\
\text { (males and } \\
\text { females) }\end{array}$ & $52 \pm 11$ & $6 \pm 3$ & $35 \pm 13$ & $23 \pm 14$ & $28 \pm 10$ \\
\hline
\end{tabular}

Values given $\pm 1 \mathrm{SD}$.

The CSF HVA and 5-HIAA concentrations were compared with those of three other groups of patients: (1) 11 miscellaneous neurological patients; (2) 13 patients in a psychiatric hospital; (3) 11 patients with Parkinson's disease. Groups 1 and 2 were submitted to lumbar puncture during neurological examination, while CSF was taken from group 3 as a preliminary to the determination of the effect of L-dopa on CSF amine metabolites (GodwinAusten, Kantamaneni, and Curzon, 1971). Atypical patients who had markedly high CSF HVA after L-dopa, but exhibiting little or no benefit, were excluded from this latter group. None of the subjects in any of the groups, including those with chorea, was, or recently had been, on drugs known to influence brain amine metabolism, such as phenothiazines, butyrophenones, tricyclic antidepressants, monoamine-oxidase inhibitors or amine depleters. Subjects with elevated CSF protein were excluded. No patients in groups 1 and 2 were suffering from movement disorders and no patients in any group were suffering from senile or presenile dementia.

\section{METHODS}

Clinical assessment of the patients with chorea was made on the ward at the Royal Hospital Annexe, Sheffield, after they had been in hospital for at least four days.

A standard proforma was used, patients being scored (from 0-2,0-3, or 0-4) with respect to functional disability by clinical examination and measured tests of walking, writing, pouring, tapping, using a peg-board, and respiratory function. A modification of the Max Hamilton depression rating was scored. Though no patients were too demented to cooperate, their answers to questions concerning functional disability were checked with a relative. The maximum possible score was 75 . Those scoring below 30 were regarded as mildly impaired, those from $30-45$ as moderately impaired, and those above 45 as severely impaired.

Cerebrospinal fluid was taken by lumbar puncture in the morning before rising with the patient in the left lateral position. The patients with Huntington's chorea had been in hospital for seven days before lumbar puncture. Eight millilitre samples of CSF were stored at $-20^{\circ} \mathrm{C}$ for the later determination of HVA and 5-HIAA. HVA was determined as previously described (Curzon, Godwin-Austen, Tomlinson, and Kantameneni, 1970) and 5-HIAA by the cysteine-phthalaldehyde method (Korf and Valkenburgh-Sikkema, 1969).

Statistical evaluations were done using standard methods, correlation coefficients being compared by the Fisher $Z$ test and partial correlations calculated as described by Snedecor and Cochran (1967).

\section{RESULTS}

Data are summarized in Table 1, and in Table 2 CSF HVA and 5-HIAA concentrations of the patients with Huntington's chorea are compared with results obtained from the three other groups of patients. The mean CSF HVA concentration of the patients with chorea is significantly less than that of the group of miscellaneous neurological patients but similar to that of the group of miscellaneous psychiatric patients. However, while the mean CSF 5-HIAA concentration of the latter group is significantly below that of the group of neurological patients and similar to that of the patients with Parkinson's disease, the 
TABLE 2

LUMBAR CSF HVA AND 5-HIAA CONCENTRATIONS IN PATIENTS WITH HUNTINGTON'S CHOREA AND OTHER CONDITIONS

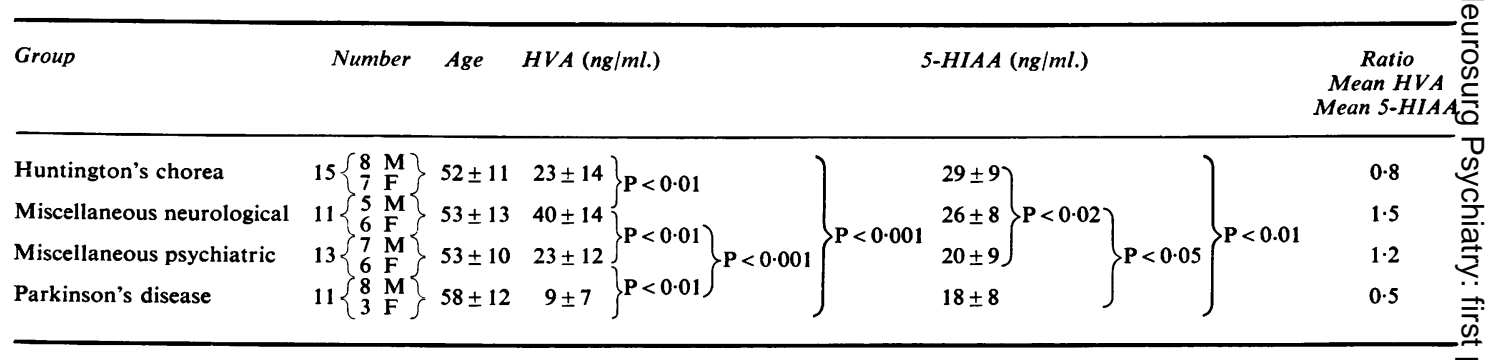

Values given $\pm 1 \mathrm{SD}$.

CSF 5-HIAA concentration of the chorea patients is similar to that of the group of neurological patients. Thus, while neither HVA nor 5-HIAA concentrations alone discriminate between all four groups, discrimination is apparent if both HVA and 5-HIAA concentrations are considered.

No group of patients showed a significant correlation between concentrations of HVA and 5-HIAA (Table 3). However, the correlation coefficient for the patients with chorea is negative, while the coefficients for the other groups are positive and numerically comparable.

TABLE 3

CORRELATIONS BETWEEN CSF HVA AND 5-HIAA CONCENTRATIONS AND BETWEEN HVA CONCENTRATIONS AND AGE

\begin{tabular}{lcc}
\hline Group & HVA $v .5-H I A A$ & HVA v. age \\
\hline Huntington's chorea & -0.22 & -0.08 \\
Miscellaneous neurological & +0.44 & -0.33 \\
Miscellaneous psychiatric & +0.30 & -0.14 \\
Parkinson's disease & +0.40 & +0.69 \\
\hline
\end{tabular}

Correlation coefficient $=r$.

$r$ for group with Parkinson's disease (HVA v. age) is different from $0(P<0.05)$. All other $r$ values are not significant.

The only group showing a significant relationship between an amine metabolite concentration and age is, somewhat surprisingly, the patients with Parkinson's disease who show a positive correlation between HVA concentration and age. None of the correlation coefficients between 5-HIAA concentration and age were significant.

When the male and female subjects were statistically evaluated as a single group, then severity and HVA concentrations did noto correlate significantly (Figure). If they weretreated as two separate groups, the correlation coefficients were much higher but, as these single $\vec{\omega}$

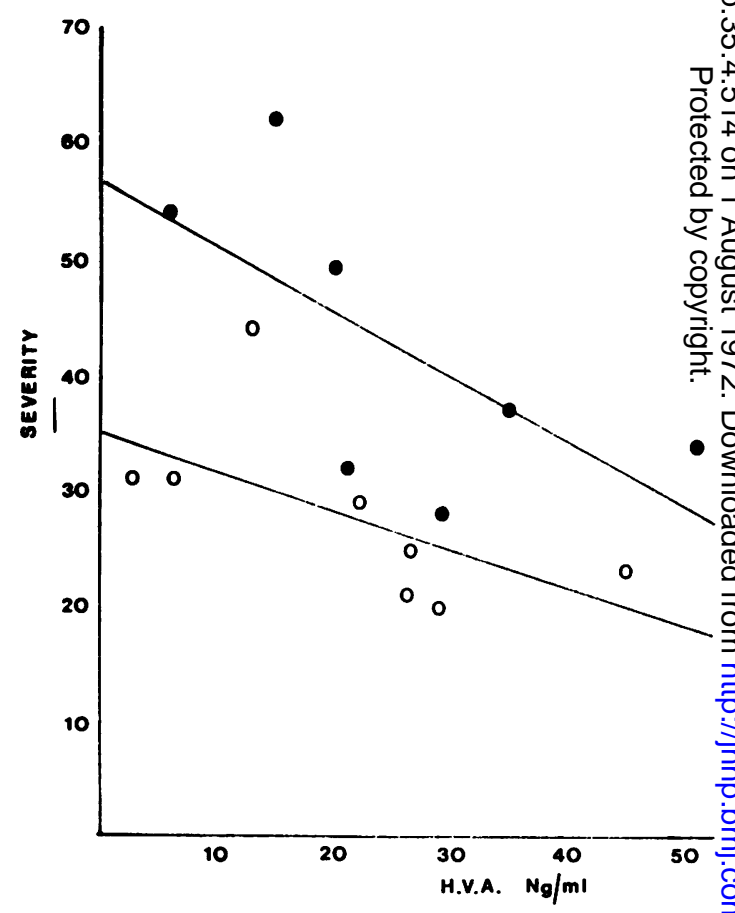

FIGURE Relationships between severity of Hunting ton's chorea and HVA concentration in the lumbars CSF. $O=$ females. $\bigcirc=$ males. Methods are described in the text. Correlations-males 0.62 , females 0:66-neither significant; males +females, $0.63 \mathrm{~N}$ $(\dot{P}<0.05)$. The combined correlation coefficient for males +females was calculated using not the absolute values but the differences between each value for severity or $H V A$ concentration and the corresponding mean value for subjects of the same sex. 
sex groups were small, correlations were not significant. However, as the coefficients for both sex groups were very similar, it was reasonable to pool data for both groups using the method of combined correlation coefficients. The correlation obtained thereby was statistically significant-that is, CSF HVA concentrations showed a significant negative correlation with severity. Correlation between HVA and age was not significant and allowing for this by the method of partial correlations did not affect the correlation between severity and HVA appreciably.

The patient with the akinetic rigid form of Huntington's chorea had a CSF HVA concentration of $3 \mathrm{ng} / \mathrm{ml}$. and a 5-HIAA concentration of $11 \mathrm{ng} / \mathrm{ml}$. (not included in the Tables or the Figure).

\section{DISCUSSION}

Evidence obtained suggests that HVA concentration in the lumbar CSF decreases as severity of symptoms of choreic patients increases and that, therefore, the net turnover in the basal ganglia of the HVA precursor dopamine and net dopaminergic activity also decrease. This finding is consistent with atrophy of the basal ganglia (Denny-Brown, 1962; Bruyn, 1968) and, taken together with the normality of the dopamine concentration therein at necropsy (Ehringer and Hornykiewicz, 1960), points to the net dopamine content of the basal ganglia being low terminally. Another possible factor decreasing HVA concentration in the lumbar sac could be dilatation of the lateral ventricle which may be considerable in Huntington's chorea (Bruyn, 1968).

In Parkinson's disease low brain DA is probably a consequence of the characteristic loss of pigmented cells in the substantia nigra (Greenfield and Bosanquet, 1953), as lesions in this region cause a fall of dopamine concentration in the caudate nucleus of the rat (Anden, Carlsson, Dahlström, Fuxe, Hillarp, and Larsson, 1964). It is possible, therefore, that the degeneration of the substantia nigra which has been sporadically reported in Huntington's chorea (Bruyn, 1968) may similarly influence CSF HVA, at least in some patients.

The indication of progressive decrease of CSF HVA is in agreement with changes in the basal ganglia also being progressive. It should be noted that, though the mean CSF HVA concentration of patients with chorea is significantly less than that of the group of patients with miscellaneous neurological disorders, some of the less severely impaired choreic subjects have HVA concentrations well within the mean \pm 1 SD range of this latter group. Thus low CSF HVA is not necessarily concomitant with chorea. Furthermore, the lowest HVA concentrations found were well within the mean \pm 1 standard deviation found for the group with Parkinsonism.

In contrast with the HVA results, the mean concentration of 5-HIAA in the CSF is similar to that of the group of miscellaneous neurological subjects. This distinguishes the group of patients with chorea from the group with the miscellaneous psychiatric disorders who had mean levels of both metabolites below those of the neurological group, possibly indicating a higher incidence of cerebral atrophic conditions in the psychiatric group.

The choreic patients are also distinguished from the group with Parkinson's disease for whom both mean CSF HVA and 5-HIAA concentrations are lower.

In general, it is found that CSF HVA and 5-HIAA concentrations are positively correlated (Gottfries et al., 1969; Pullar, Weddell, Ahmed, and Gillingham, 1970), although in the present study the positive correlations for the individual non-choreic groups were below the level of significance. However, the correlation for the choreic group was negative and, though again not significant, is a further suggestion of defective dopamine metabolism in chorea rather than a defect in both 5-hydroxytryptamine and dopamine metabolism or in transport of their metabolites.

The evidence that brain DA turnover is low in severe chorea contrasts with the choreiform movements which can occur when the dopamine precursor L-dopa is given to patients with Parkinson's disease (Cotzias, Papavasiliou, and Gellene, 1969; Calne, Stern, Laurence, Sharkey, and Armitage, 1969; Godwin-Austen et al., 1969). These movements and the precipitation by L-dopa of chorea in subjects with the akinetic rigid form of Huntington's chorea (Barbeau, 1969; Klawans, Paulson, and Barbeau, 1970) suggest that over-production of dopamine might be involved in Huntington's chorea. Furthermore, the effects of various drugs are consistent with decreased synaptic dopamine concentration being beneficial in chorea. Thus phenothiazines (Cohen, 1962), which probably block dopamine receptors, and the amine depleters reserpine and 
tetrabenazine (Pakkenberg, 1968; Dalby, 1969; Sharpe and Gumpert, 1971) all have a therapeutic effect.

The low CSF HVA concentrations found appear paradoxical unless dopaminergic activity as such is less relevant to the genesis of the chorea than are ratios between it and activities of other neurohormones. As the degeneration in the basal ganglia may well involve cell bodies of cholinergic neurones, decreased cholinergic activity may play a part, as is suggested by the beneficial effect of physostigmine (Aquilonius and Sjostrom, 1971). If the chorea depends upon the relative degree of disturbance of different neuronal systems, then it is apparent that decreased activity of two systems may result in either a decrease or increase of the ratio of their activities. It is possible that alteration of the ratio in one direction is associated with chorea, while alteration in the opposite direction is associated with the less common akinetic rigid Huntington's chorea. It is, therefore, of interest that, while severely choreic patients had low CSF HVA but normal 5-HIAA, both of these amine metabolites were low in the CSF of the single patient with severe akinetic rigid symptoms, the biochemical picture being identical with that found in Parkinson's disease.

We are deeply grateful to Dr. James Carson for his continual encouragement and support. We would like to thank Mrs. B. D. Kantamaneni for her skilled technical assistance. G. Curzon is in receipt of a grant from the Ministry of Health and Social Security Clinical Research Fund. J. Gumpert and D. Sharpe are supported by The Ryder Briggs Memorial Foundation. We would like to thank Dr. James Carson and Dr. Peter Bradshaw and the consultant psychiatric staff of The Middlewood Hospital who have allowed us to study their patients. Roche Laboratories Ltd have generously provided additional financial support.

\section{REFERENCES}

Andén, N.-E., Carlsson, A., Dahlström, A., Fuxe, K., Hillarp, N.-A., and Larsson, K. (1964). Demonstration and mapping out of nigro-neostriatal dopamine neurons. Life Sciences, 3, 523-530.

Aquilonius, S.-M., and Sjostrom, R. (1971). Cholinergic and dopaminergic mechanisms in Huntington's chorea. Life Sciences, Part 1, 10, 405-414.

Ashcroft, G. W., Dow, R. C., and Moir, A. T. B. (1968). The active transport of 5-hydroxyindol-3-ylacetic acid and 3-methoxy-4-hydroxyphenylacetic acid from a recirculatory perfusion system of the cerebral ventricles of the unanaesthetized dog. Journal of Physiology, 199, 397-425.

Barbeau, A. (1969). L-dopa and juvenile Huntington's disease. Lancet, 2, 1066.
Bernheimer, H., Birkmayer, W., and Hornykiewicz, O. (1966). Homovanillinsäure im Liquor cerebrospinalis: Unter- $Z$ suchungen beim Parkinson-Syndrom und anderen Erkran-通 kungen des ZNS. Wiener klinische Wochenschrift, 78, 417419.

Bruyn, G. W. (1968). Huntington's chorea. Historical, clinical and laboratory synopsis. In Handbook of Clinica? Neurology, 6, pp. 298-378. Edited by P. J. Vinken and G. W. Bruyn. North-Holland: Amsterdam.

Calne, D. B., Stern, G. M., Laurence, D. R., Sharkey, J., and Armitage, P. (1969). L-dopa in postencephalitic Parkinsonism. Lancet, 1, 744-747.

Chase, T. N., Schnur, J. A., and Gordon, E. K. (1970). Cerebrospinal fluid monoamine catabolites in drug- $\overrightarrow{\overline{\vec{F}}}$ induced extrapyramidal disorders. Neuropharmacology, $9 \stackrel{9}{\rightarrow}$ 265-268.

Cohen, N. H. (1962). The treatment of Huntington's chorea음 with trifluoperazine (Stelazine). Journal of Nervous and Mental Disease, 134, 62-71.

Cotzias, G. C., Papavasiliou, P. S., and Gellene, R. (1969). Modification of Parkinsonism-chronic treatment with L-dopa. New England Journal of Medicine, 280, 337-345. -

Curzon, G., Godwin-Austen, R. B., Tomlinson, E. B., and. Kantamaneni, B. D. (1970). The cerebrospinal fluid $三$ homovanillic acid concentration in patients with Parkinson- $\vec{\omega}$ ism treated with L-dopa. Journal of Neurology, Neuro? surgery, and Psychiatry, 33, 1-6.

Curzon, G., Gumpert, E. J. W., and Sharpe, D. M. (1971). Amine metabolites in lumbar cerebrospinal fluid of humans with restricted flow of cerebrospinal fluid. Nature; New Biology, 231, 189-191.

Dalby, M. A. (1969). Effect of tetrabenazine on extrapy通 midal movement disorders. British Medical Journal, 422-423.

Denny-Brown, D. E. (1962). The Basal Ganglia and theirRelation to Disorders of Movement. Oxford Universi Press: London.

Ehringer, H., and Hornykiewicz, O. (1960). Verteilung v8n Noradrenalin und Dopamin (3-Hydroxytyramin) Gehirn des Menschen und ihr Verhalten bei Erkrankungon $\overrightarrow{0}$ des extrapyramidalen Systems. Klinische Wochenschrif, N 38, 1236-1239.

Godwin-Austen, R. B., Kantamaneni, B. D., and Curzon, G. (1970). Comparison of benefit from L-dopa in Parkinsonism? with increase of amine metabolites in the cerebrospinal fluid. Journal of Neurology, Neurosurgery, and Psychiatry, $\overline{\mathrm{O}}$ 33, 219-223.

Godwin-Austen, R. B., Tomlinson, E. B., Frears, C. C., and Kok, H. W. L. (1969). Effects of L-dopa in Parkinson's disease. Lancet, 2, 165-168.

Gottfries, C. G., Gottfries, I., and Roos, B. E. (1969). 3 Homovanillic acid and 5-hydroxyindoleacetic acid in the cerebrospinal fluid of patients with senile dementia, presenile dementia and Parkinsonism. Journal of Neurochemistry, 16, 1341-1345.

Greenfield, J. G., and Bosanquet, F. D. (1953). The brain $\frac{7}{0}$ stem lesions in Parkinsonism. Journal of Neurology, Neurosurgery, and Psychiatry, 16, 213-226.

Guldberg, H. C. (1969). Changes in amine metabolite concentrations in cerebrospinal fluid as an index of turn- $ᄋ$ over. In Metabolism of Amines in the Brain. Proceedings of the Symposium of the British and Scandinavian Pharma-O cological Societies, Edinburgh, July 1968, pp. 55-64. Edited by G. Hooper. Macmillan: London.

Guldberg, H. C., and Yates, C. M. (1968). Some studies of the effects of chlorpromazine, reserpine and dihydroxy- $\bar{N}$ phenylalanine on the concentrations of homovanillic acid, or 3,4-dihydroxyphenylacetic acid and 5-hydroxyindol-3- N ylacetic acid in ventricular cerebrospinal fluid of the dog $\mathrm{N}$ using the technique of serial sampling of the cerebrospinal $\mathrm{\omega}$ fluid. British Journal of Pharmacology, 33, 457-471.

Hornykiewicz, O. (1966). Dopamine (3-hydroxytyramine) and brain function. Pharmacological Reviews, 18, 925-964. 
Klawans, H. C., Paulson, G. W., and Barbeau, A. (1970). Predictive test for Huntington's chorea. Lancet, 2, 11851186.

Korf, J., and Valkenburgh-Sikkema, T. (1969). Fluorimetric determination of 5-hydroxyindolacetic acid in human urine and cerebrospinal fluid. Clinica Chimica Acta, 26, 301-306.

Pakkenberg, H. (1968). The effect of tetrabenazine in some hyperkinetic syndromes. Acta Neurologica Scandinavica, 44, 391-393.

Pullar, I. A., Weddell, J. M., Ahmed, R., and Gillingham, F. J. (1970). Phenolic acid concentrations in the lumbar cerebrospinal fluid of Parkinsonian patients treated with Ldopa. Journal of Neurology, Neurosurgery, and Psychiatry, 33, 851-857.

Rinne, U. K., Sonninen, V., and Palo, J. (1966). Excretion of homovanillic and vanilmandelic acid in patients with extrapyramidal disorders. Psychiatria Neurologia, 151, 321-327.

Sharpe, D. M., and Gumpert, J. (1971). Unpublished observations.

Snedecor, G. W., and Cochran, W. G. (1967). Statistical Methods, 6th edn. Iowa State University Press: Iowa.

Sourkes, T. L., Pivnicki, D., Brown, W. T., Wiseman-Distler, M. H., Murphy, G. F., Sankoff, I., and Saint-Cyr, S. (1965). A clinical and metabolic study of dopa $(3,4-$ dihydroxyphenylalanine) and methyldopa in Huntington's chorea. Psychiatria Neurologia, 149, 7-27.

Williams, C. M., Maury, S., and Kibler, R. F. (1961). Normal excretion of homovanillic acid in the urine of patients with Huntington's chorea. Journal of Neurochemistry, 6, 254-256. 